\title{
Cultural Textual Analysis in Tudak Cear Cumpe
}

\author{
Yuliana J. Moon ${ }^{1}$, YosefinaHelenora Jem² ${ }^{2}$ Hieronimus C. Darong ${ }^{3}$, YustusSentus Halum ${ }^{4}$ \\ Universitas Katolik Indonesia Santu Paulus Ruteng ${ }^{1234}$ \\ \{jemyosefina@gmail.com $\left.{ }^{1}\right\}$
}

\begin{abstract}
This is a cultural textual linguistics research of Manggaraian ritual ceremony cearcumpe. The research deals much with an anlysis of lexical cohesion of three selected ritual texts in mid- Manggarai by relying much on cultural linguistics approach. The research would be of benefit to Manggaraian language existence as well as teaching and learning English as a foreign language. The main data to be concerned with is the utterenacesuttered by spokesman in tudak cear cumpe which in turn considered as the texts to be analyzed. In relation to this, an observation (participant observer), recording and interview had been conducted to obtain the data. The data, then, were analyzed qualitatively through three procedures that is reduction, display and verification. The result indicates that repetition is the most lexical used by the author. It has 49 utterances $(54 \%)$ in total. However, the lowest lexical cohesion is superordinate where there is only 4 utterances (4\%). Repetition covers more than half data among the other devices.
\end{abstract}

Keywords: text; culture; cearcumpe

\section{Introduction}

Language and thought in behavioral entities according to Sapir-Whorf, known as the Sapir-Whorf hypothesis, views language as a mirror of culture. In other words, human language represents the concepts contained in his mind as a reference to his world through grammatical and semantic categories [1]. So, it can also be said that the regularity of an utterance is a reflection of the regular way of thinking of humans.

The utterances in the traditional ceremonies of the Manggarai community are thought to have regularity in form and meaning. This is evidenced by the attitude of the listeners who always enjoy these utterances. These utterances are beautiful to hear. People who listen to the speech can get carried away. They thoroughly enjoyed each utterance. The attitude of the listeners, of course, cannot be separated from the ability of a speaker to produce his speech. Based on this, the researcher wants to analyse why the speech in traditional ceremonies is enjoyed by listeners. The researcher wants to prove whether it is true that the utterance does have a harmonious relationship of meaning. To prove the harmony of the speech, the researcher will explore the speech in text form.

A text is said to be good if it meets the requirements for the integrity of form and meaning. The integrity of a text is seen from the sentences that are arranged harmoniously. The existence of the first sentence is supported by the second sentence, the existence of the first and second sentences is supported by the third sentence, and so on. The similarity of meaning and form of sentences reflects the integrity of a text supporting the same topic. One of the benchmarks to see that wholeness is with language markers, namely lexical cohesion. 
Semantically, the relationship between elements in the discourse is known as lexical cohesion [2]. According to Kushartanti [3], lexical cohesion is the semantic relationship between discourse-forming elements by utilizing lexical elements or words. In general, lexical cohesion is in the form of free words or phrases that can maintain a cohesive relationship with the sentences that precede or follow them. There are two kinds of lexical cohesion, namely reiteration and collation. Reiteration is the cohesion used by repeating a proposition or part of a proposition. Reiteration includes repetition, synonyms, superordinate's, antonyms, conjunctions. Second, word collocation which shows the closeness of place (location). Lexical cohesion can be a benchmark, the quality of a text because a text is largely determined by the choice of words in its sentences. If in a text, there is a choice of words that are repeated, it can be said that the text does refer to the same topic. If in a text, there are synonyms, then the text also supports the same topic. Likewise, other lexical cohesion markers.

Manggarain cear cumpe is a linguistic as phenomenon to be concerned with. It is a phenomenon of linguistics that covers on how language usage deals much with certain contexts of utterance. The context of cear cumpe for Manggraian is highly considered to be as a special occasion in which certain language as a culture shows paramount role textually of legalizing a new baby born to be accepted formally in terms of culture and Manggarain belief. This ritual is quite important and must be passed through in for Manggaraian new baby born for the sake of a warm and life safety. This as such, is important and does change the social status of the baby; it also indicates the status even the greatness of the parents. Manggarain new baby cear cumpe is a moment of how perspectives of Manggarain people transactioned to the exstence of culture from which they got some values in conducting the life. Then, the language used are seen as a product in society encountering with the culture value which has been inherited by Manggaraian's ancestor from a long time ago.

With regard to the process of conducting cearcumpe, language usage "textually" or ritual text uttered by the spokeman is on the top rank of going it smoothly. This is so, as it has been mentioned, because of its paramount role. The role of the uttered text as such must be functioned as a fully communicative agreement in that very special unforgettable speech event. It contains the value of demonstrating good manners or etiquette and is considered as a prayer to our ancestors of the clan where the new baby born belong to. When the spokeman utters meaningfully, then that person illustrates the value of sense, hope, manners or etiquette, social value of being real Manggarain as the communities in which he or she involved as a part of members in the future.

Therefore, when it is uttered or said, there should be a notice toward the information being conveyed, and the effect of the words that being used. When it is uttered, the one who is in charge of that must be able to choose one of many different kinds of topic he wants to say, how he says it and the specific sentences types, words, and sounds that best bond the topic and the way of saying it. How is said is what is said. It is in line with Wardaugh [4] that the way we say something is as important as the point we want to say. To facilitate this, certain conventions is highly expected. The convention makes that language used become a united text of which the lexical cohesion as one of the elements must be functioned and considered as the convention as such.

The speech in the Cear Cumpe event generally carries the same theme, namely giving thanks to God and the ancestral spirits and asking for protection from God and the ancestral spirits. With this theme, a traditional speaker will reveal goet (figurative expressions) and prayers that refer to these two themes. So, it is suspected that in the speech, there is a marker of lexical cohesion. 
The cearcumpeevent is the dismantling of the fireplace used by a mother to warm herself and her baby during childbirth. In ancient times, people used fireplaces for heating during childbirth. The dismantling of the hearth (cearcumpe) means that a baby is ready to be shown to the wider family and society. This event also became an event for naming a child, $[5]$.

\section{Research Methods}

This study employs descriptive qualitative research based on certain theory. Qualitative research is a study that aims at investigating the quality of relationship, activities, situations or materials. By referring to this, the objects of this research were the three selected Manggarain ritual text in tudakcearcumpe from which the researchers got the main source of information that in turn, considered as the data. The descriptive qualitative research, in this case, was used to describe and analyse the lexical cohesion of the three ritual texts in cearcumpe by relying much on cultural linguistics approach.

According to Miles and Huberman [6], the main sources of data in qualitative research are verbal linguistics (words and action) and the other such as documents as supporting sources. In relation to this research, the words or texts of three selected ritual texts in cear cumpe are the main concern. It is about language usage especially utterances employed by the spokesman.In doing this research, the researcher observed and interviewed the spokesman to collect the data. Consequently, the instrument used is video recorders. This was done since the object to be analysed is the utterance of the spokesman which in turn was considered as the texts to be concerned with. The position of the researcher in this context will be as "participant observer" in which the researcher just observed, listened and recorded what and how the spokesmen utter the texts. This as such was essential in determining the types of lexical cohesion used.

Data analysis in qualitative research is done when the process of data collection held, and after data is collected. Mahsun [7] states in analyzing data, the researcher should complete three procedures, namely data reduction, data display, and verification. In data reduction, the researcher summarizes, chooses the subject matters, focuses on things that are important, looks for themes and patterns. Thus, data reduction will supply an understandable picture and enables researchers to run further data collection, and search if necessary. In data reduction, the researcher transcribed the result observation. After transcribing, the researcher then simplified the data by determining the lexical cohesion found in the ritual cearcumpe text to be labelled as a fully communicative agreement.

In the past, narrative text has been found as the most frequent form of display data for qualitative research data [7]. In this research, the researcher displays the data in form of table based on lexical cohesion found.

\section{Conclusion drawing/Verification}

The last procedure in analyzing data according to [8] is drawing the conclusion. In this step, the researcher answered the research problems raised in the introduction part namely the use of lexical cohesion in the cultural text of ritual cear cumpe. 


\section{Results and Discussion}

The researchers present the results of analysis that include the lexical devices in terms of reiteration and collocation used in the ritual textofcearcumpe. Making a clear analysis is an important point in discussing a research result. That is why, before having deep discussion on the frequency and regulation, the reserachers want to display the occurances of each type lexical cohesion. The following part is the analysis of the lexical cohesive devices used in the ritual text of cear cumpe to see how lexical cohesion helps to make the whole discourse coherent.

\subsection{Results}

The following tables requires data on how each types of lexical cohesion represented in the ritual text of tudak cear cumpe.

Table 1. The Occurrence of Repetition in the Text

\begin{tabular}{llc}
\hline \multicolumn{1}{c}{$\begin{array}{c}\text { Lexical } \\
\text { Items }\end{array}$} & \multicolumn{1}{c}{\begin{tabular}{c}
\multicolumn{1}{c}{$\begin{array}{c}\text { Contextual } \\
\text { Meaning }\end{array}$} \\
$\begin{array}{c}\text { Frequency of } \\
\text { Repetition }\end{array}$
\end{tabular}} & 3 \\
Denge & Listen & 3 \\
Pa'ang be le tana bawa & A reference for the dead (spirits of the ancestors) & 8 \\
Wori agungaran & God, the owner of life & 6 \\
Beki & Body (in some utterances it can be translated as persons & 2 \\
ganuk & A rooster & 2 \\
Ela & A pig & 5 \\
Anak & A child & 2 \\
To'a, empo, ase, ede & ways how family and relatives acknowledge the child & \\
& based on their family tree pose: nephew, grandchild, & 6 \\
Paing & sister/brother & 2 \\
Dung agudedek & (to) ask & 3 \\
Beti & Referring God, the Creator & 3 \\
Lasa & Illness & 2 \\
Torok & Illness & 2 \\
Lesoho'oh & words (speech) & \\
\hline
\end{tabular}

Table 2. The Occurrence of Synonymy in the Text

\begin{tabular}{lll}
\multicolumn{1}{c}{$\mathbf{1}$} & \multicolumn{1}{c}{ Lexical Items } & Contextual Meaning \\
\hline Ata pa'ang be le & Ata tana bawa & The dead (ancestors) \\
Nekiweki & Samaranga & To gather round \\
Mekasaiweru & Anaksaiweru & New baby born \\
Mori jari & Mori ata dung agudedek & God the Creator of all \\
Lasa & Beti & Illness \\
Mbaru & Niang & House \\
Niang took & Kilo & Bedroom/ place to sleep \\
Tura & Torok & Words (speech) \\
\hline
\end{tabular}

Table 3. The Occurrence of Antonymy in the Text

\begin{tabular}{ccl}
\hline Lexical Items & Antonyms & \multicolumn{1}{c}{ Contextual Meaning } \\
\hline Ba le & Ba wa & $\begin{array}{l}\text { Locative markers (as northern vs. southern, eastern vs. } \\
\text { western) }\end{array}$ \\
Anakrona & Anakwina & $\begin{array}{l}\text { Family connection resulted from marriage (members of } \\
\text { Fam }\end{array}$
\end{tabular}




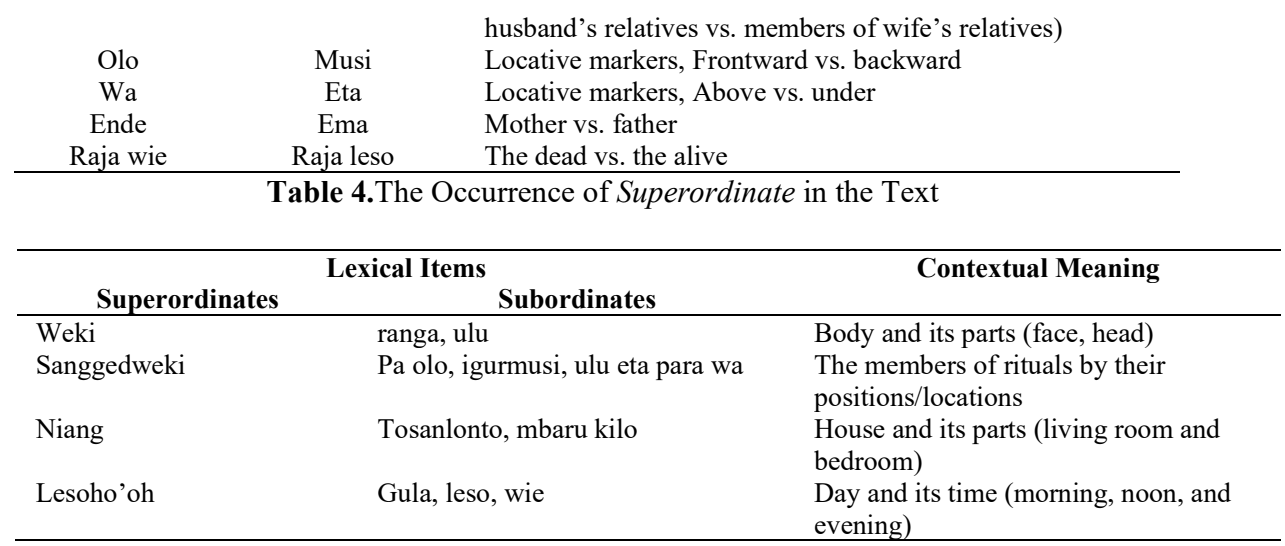

Table 5. The Occurrence of Collocation in the Text

\begin{tabular}{c}
\hline Collocations \\
Tana bawa \\
Mori agungaran \\
Nekiweki \\
Samaranga \\
Anakrona, anakwina \\
Anak, toa, empo, ase \\
Mekasaiweru \\
Imangnehorimang \\
Kimpurnehokiwung \\
Lasa ranga \\
Betiweki \\
Mori ata dung agudedek \\
Mori jari \\
Uwahaengwulang \\
Langkashaeng tala \\
Lagalangkas \\
Endeaguema \\
Lasan tana \\
Kolangtosan \\
Rindadianiang \\
Anaksaiweru \\
Uwagulabokleso \\
Pingadia \\
Tibadia
\end{tabular}

\subsection{Results}

The concept of cohesion is closely related to semantic field. It refers to relation of meaning that exists within a text, and to define it as a text. Cohesion happens where the construal of some elements in the text depends on that of another; the one requires the other, in the sense that it cannot be effectively interpreted except by identifying their connections [8].
In
addition
Brown
\& Yule
[9]
explained
that

the relationship between propositions that is indicated explicitly by the semantic elements insi de the utterances, which creates a discourse, is referred to as cohesiveness. Here, cohesive relationships within a text are set up where the interpretation of some elements in the interpretation of some elements in the discourse are reliant one another.

On the other hand, The cohesive effect achieved by vocabulary selection is referred to as lexical cohesive devices. The development of a discourse is not solely dependent on grammatical considerations; lexical choice also plays a vital role. It suggests that the 
connection between sentences can be established through word/lexical choices, because the construction of a discourse is aided not only by grammatical variables, but also by lexical choices. It signifies that the sentences are constructed entirely from word/lexical choices [10]. McCharty [11], in this sense, explain that lexical cohesion is "Related vocabulary items occur across clause and sentence boundaries in written text".

Below is the sum of lexical cohesion occurrences in the text of Cear Cumpe

Table 6. The Frequencies of Lexical Cohesion

\begin{tabular}{clc}
\hline NO & $\begin{array}{c}\text { Types of } \\
\text { Lexical Cohesion }\end{array}$ & Numbers \\
\hline 1 & Repetition & 49 \\
2 & Synonymy & 8 \\
3 & Antonymy & 6 \\
4 & Super ordinate & 4 \\
5 & Collocation & 24 \\
\hline
\end{tabular}

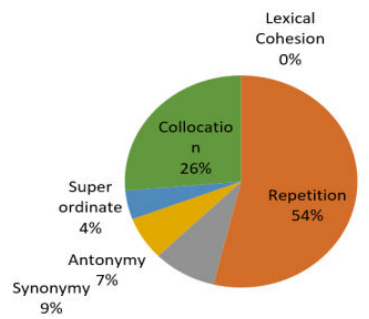

There are 91 occurrences of lexical cohesion in the data that have been analyzed using the five categories of lexical cohesion, as shown in the table and chart. Table 6 shows the order of the most common findings to the least common findings, starting with repetition, collocation, synonymy, antonymy, and superordinate. As a result, repetition is the most common type (54 percent), implying that the speaker is attempting to make the audience understand the content of the text without any reduction or interruption. Meanwhile, superordinate has the lowest ranking (4 percent), indicating that it is difficult to locate in a given text.

\section{Repetition}

Words that are repeated in the text, as well as words that have changed to express tense or number, are referred to as repetition [12]. In other terms, repetition is the use of the same words, idioms, or sentences over and over again. Repetition, which is frequently combined with the device of parallelism, contributes significantly to the texture, whether in Manggaraian or English. There are rarely repetitions of clauses or sentences in the Cear Cumpe Text. The reason for this is because parallelism is more commonly utilized in other public speeches than in ceremonial speeches like campaign speeches and inauguration addresses, which must be strong and forceful in order to successfully appeal to the audience's emotions.

The speech of Cear Cumpe aims at warming people at that special occasion (welcoming the new born baby in the family), as a result, there is no repetition of clauses or sentences in the speech. However, there are numerous word and phrase repeats.. The frequencies of their appearance can be figured out from the following chart: 


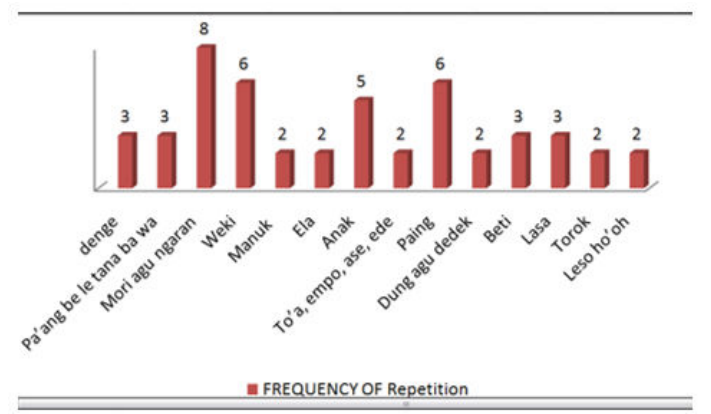

Fig1. Frequency of Repetition

In Cear Cumpe, the whole speech is around the topic of "thank God for a new baby born". It involves sense of asking blessings from God and the spirit of the ancestors to guard the child. This is clear in the initial part of the text:

e... dengeele meu ata pang ba le agu tana bawa, ngitukoleLite Mori agungggaran.

Lesohoohaminekiweki, samaranga, anakrona, anakwina, nang lawing sanggedweki pe pa olo, aguigurmusi, ngitukolesanggedwekiatapenong ulu eta agu para wa. Tara pe le saulaingmanukagu pongo laingela, ai lesohoogilamirebonganak, toa, empo, aseedehami, mekasaiweruatapoligangasangsama, ngasang "Jeliana", atatambangweki one kilo edeLausagu Eli.

Denge Lite Mori agungaranata dung agudedek, one mairebonganak, toa, empo, aseedehamilesohoo, paingelehamiwekineki one Ite Mori jari, kudutwekinkombobesiaguulunwatusila,

kudutwakarnimangnehorimangagukimpurnehokiwung, kududnekalasanrangaagubetiwekin.

The word "Mori agu Ngaran" means God the Owner, therefore, appears as the most repeated phrase ( 8 times) without doubt followed by the mode of speech that is asking (paing) blessing for the child (anak). The text is also an asking for ancestors to grant the child healthy and take the child away from illness. Thus the speaker would sketch what kind of request he asked for their ancestors. So, words like ata pang be le, beti, and lasa are common sight. The writer or speaker's thought or feelings are also emphasized by repetition of words. For example, the word "weki" is frequently used in this dialect, and it refers to a spirit of cooperation.

\section{Synonymy and Antonymy}

The association between words with similar meanings is known as synonymy [12]. As a result, it reduces cohesion between words that have the same or similar meanings. Because they share the same or comparable logical concepts, these words are mixed in the same paragraph. They complement one other in meaning, not only acting as textual ligaments but also assisting in the improvement of the text's expressive energy.

The following excerpt is taken from the text:

e... dengeele meu atapangbaleagutanabawa, ngitukoleLite Mori agungggaran. Lesohoohaminekiweki, samaranga, anakrona, anakwina, nang lawing sanggedwekipe pa olo, aguigurmusi, ngitukolesanggedwekiatapenong ulu le agu para sili.

In this instance, ata pang ba le here means the same as ata tana ba wa, which both represent those who have died. In similar line, the items neki weki has the co-synonym as 
sama ranga which represents the togetherness. Because these two statements have the same meaning, the second sentence is more coherent with the first. On the other hand, antonymy can produce a strong contrast effect, emphasizing the message they represent and bolstering the expressive force. Antonym is words which are in some sense opposite in meaning and "often thought of in the same breath as synonymous, but they are in fact very different" [13].

The deliberate arrangement of contrasting words or concepts in balanced structural patterns to produce power and emphasis is usually referred to as antonym in political terms. However, ritually speaking, because of its genre, antonymy is rarely employed. Antonymy appears in this speech six times and among them, four are opposites of locative markers, for example

1. Sangged weki pe pa olo, agu igurmusi,

2. Ngitu kole sangged weki ata penong ulu eta agu para wa.

\section{Superordinate}

From a broad perspective, the lexical cohesive device hyponymy or meronymy, which corresponds to the incorporation of one class in another, can also be referred to as superordinate. This lexical cohesive device is less used in the text of Cear Cumpe, but we can still find a few examples.

.....paing le meu one Mori agungarankudutrindadianiang, kudutnekarabaaguretang, kudutnekarojongniang took, agunekakolangtosanlonto, one mbarukilo.

In the utterance, niang took, tosan lonto, and kilo are parts of house (niang/mbaru)which is a partnership of inclusion The employment of this lexical cohesive technique unifies the texture, making it more logical as it progresses from general to specific, and makes it easier for the addressees to follow the speaker's mental process

\section{Collocation}

Collocation is a systematic relationship between two words that is small and difficult to evaluate on text. This includes not just synonyms, close synonyms, and superordinates, but also complementary pairs of opposites of many kinds [8]. Collocation is a text-bound relation's cohesive device in the sense that some items tend to occur in the same semantic setting. Certain terms tend to co-occur when we discuss a topic in a text, whereas others are unlikely to appear. There is no doubt that they contribute to the formation of text because of their semantic link.

We can find several examples in the text of Cear Cumpe:

1. Tara pe le sau laing manuk agu pongo laing ela, ai leso hoo gi lami rebong anak, toa, empo, ase ede hami, meka sai weru ata poli gangasangs ama, ngasang "Jeliana”, ata tambang weki one kilo ede Laus agu Eli.

2. e... denge ele meu ata pang ba le agu tana bawa, ngitu kole Lite Mori agu ngggaran. Leso hoo hami neki weki, sama ranga, anak rona, anak wina, nang lawing sangged weki pe pa olo, agu igur musi, ngitu kole sangged weki ata penong ulu le agu para sili.

In the first instance, anak, toa, empo, ase,ede and meka sai weru develop a collocation bond, which comprises of the relationship between family tree members and the new born child Similarly, a collocation bond is established between a complimentary pair in the second scenario, Mori agu Ngaran, which means God The Owner and gurdian of Life [14]. Moreover, although anakrona and anakwina is a lexical cohesive technique that can be used to form ties between languages that occur in the same semantic region.. 
The words of a semantic field are not definitely synonymous, but they are joined together by a common semantic feature by certain reasons. In the text of Cear Cumpe, or in other forms of ritual speeches in Manggarai, collocations are also specifically bounded through rhythmical items (poetic expression) which cause the collocation fixed to utter. For example: uwahaengwulangagulangkashaengntala. In this example, "wulang" and "ntala" have the same semantic meaning and all remind people of their wish for the child (to grow reaching the moon and the star), therefore, they belong to collocation as well. In this situation, any two lexical items with comparable collocation patterns, that is, those that tend to appear in similar contexts, will generate a cohesive force if they exist in neighboring sentences.

\section{Conclusion}

Based on the statistics, it's clear that repetition is the most common type of lexical cohesiveness used by the author, with 49 instances (54\%) in total. Superordinate cohesion is the least common type of lexical cohesion, with only four instances (4\%). Repetition is the most common lexical cohesive device, accounting for over half of the five. As previously stated, the CearCumpe speech, as a Manggarai ritual speech, differs from other speeches in that it requires more logic and passion. CearCumpe's speech is more akin to a question-andanswer session to greet the new child, offering encouragement, hope, and inspiration to the audience.

Despite the lack of powerful parallelism, repetition is prevalent in the discourse. The audience will easily grasp the point of the speech if you use repetition. The whole conversation in the 2015 Christmas Broadcast, for example, is centered on "Asking God for the Blessing." As a result, the word "Mori agungaran" appears several times throughout this speech. On the one hand, repetition might draw attention to the speech's main argument, making it easier for the audience to understand. Repetition of certain words or phrases, on the other hand, makes the context more closely connected and cohesive, making the entire speech denser and more well-organized.

However, there are situations when idioms with comparable meanings are used to replace one word. The words "lasa" and "beti" are both used in the text, for example. The usage of synonymy avoids word choice simplification and improves the readability of the context. This lexical technique encompasses both synonymy and antonymy, giving it a broader scope. Although the usage of synonymy is the third most common, the use of antonymy is less common, possibly because the CearCumpe genre does not require as much contrast of particular phenomena as other sorts of occasions. Collocation, on the other hand, takes up the second-largest share of the market $(26 \%)$.

Collocations can help to connect the context and make the speech more cohesive if they are used correctly. There are collocation expressions in the speech such as "ende and ema" (mother and father) and "eta and wa" (above and below). The least often used of the five devices, superordinate, is not frequently utilized in speech. It's possible that this is due to the fact that this equipment is more complicated and difficult to use. Alternatively, the usage of superordinate may be limited by the speech's genre.

\section{References}

[1] Kustyarini: Language and Character Formation. Likhitaprajna Scientific Journal, Volume 19, Number 2. Malang: Wisnuwardhana University (2017)

[2] Sumarlam: Theory and Practice of Discourse Analysis. Surakarta: Pustaka Chakra (2003) 
[3] Kusharanti, et al.: The Enchantment of Language: The First Steps to Understanding Linguistics. Jakarta: Gramedia (2005)

[4] Wardhaugh, R.: An Introduction to Sociolinguistics. Second Edition. Oxford: Blackwell Publishers Ltd (1996)

[5] Nggoro, Adi M: Manggarai Culture at a Glance. Ende: Nusa Indah (2006)

[6] Miles M. and Huberman M.A: An Expanded Source Book; Qualitative Data Analysis Research, (2nd ed) London: Sage Publications Ltd. (1994)

[7] Mahsun, M.S.: MetodePenelitan Bahasa: Tahapan Strategi, Metode, dan Tekniknya. Jakarta: Raja GrafindoPersada. (2005)

[8] Halliday, M.A.K. and Hasan, R: Cohesion in English. London: Longman (1976)

[9] Brown, G. and Yule, G: Discourse Analysis. Cambridge: Cambridge University Press (1983)

[10] Chojimah, Nurul: "Let's Analyze Discourses." Tulungagung: State Islamic (2014)

[11] Michael, McCarthy: "Discourse analysis for language teachers." (1991).

[12] Paltridge, Brian, and Jill Burton: Making sense of discourse analysis. Gold Coast ( 2000)

[13] Crystal, David: "The Cambridge encyclopedia oflanguage." UK: Cambridge University (1987).

[14] Bustan, F., Semiun, A., \&Bire, J. The Cultural ConceptualisationOfManggarai People On The Origin Of Life: Cultural Linguistic Analysis. Academic Journal of Educational Sciences, 4(1), 1319. (2020). 